\title{
MRI Assessment of Degeneration of Multifidus and Erector Spinae Muscles in Patients With Chronic Low Back Pain
}

Alikemal Yazici ( $\square$ alikemalyazici@hotmail.com )

Near East University

\section{Tuba Yerlikaya}

Near East University

Adile Oniz

Near East University

\section{Research Article}

Keywords: Low back pain, Musculus multifidus, Musculus erector spinae, Cross-sectional area, Fat infiltration, Magnetic Resonance Imaging

Posted Date: May 28th, 2021

DOI: https://doi.org/10.21203/rs.3.rs-549319/v1

License: (a) (1) This work is licensed under a Creative Commons Attribution 4.0 International License. Read Full License 


\section{Abstract}

Background: The aim of this study was to investigate the degeneration of lumbar musculus multifidus (L.MF) and lumbar musculus erector spinae (L.ES) muscles in healthy individuals and patients with mechanical low back pain and lumbar discopathy without root compression (radiculopathy), and to examine the relationship between low back pain by comparing the results according to gender, pain and lumbar segments between the groups.

Methods: The study included 30 healthy individuals (Group 1), 30 patients with mechanical low back pain (Group 2) and 30 patients with lumbar discopathy without root compression (radiculopathy) (Group 3). Pain severity was evaluated using a Visual Analogue Scale (VAS). Right and left L.MF and L.ES crosssectional areas (CSA), total cross-sectional areas (TCSA $=$ L.MF+L.ES), fat infiltrations, and asymmetries between the right and left sides were evaluated. L.MF and L.ES muscles CSA and TCSA, fat infiltrations, asymmetries between the right and left sides were evaluated in the patients at the L3-S1 level, in axial Magnetic Resonance Imaging.

Results: The mean value of the CSA differed between the groups only in the right L.MF and in the healthy group ( $p=0.011)$. No statistically significant difference was observed between the TCSA values of the groups, but a significant difference was found between the groups in terms of fat infiltration in right and left L.MF and left L.ES ( $p=0.011, p=0.001, p=0.027$, respectively). When CSA and TCSA were examined according to gender within the group, the values were found to be significantly higher in males $(p<0.001)$. The CSA and TCSA values of L.MF and L.ES differed between segments (L3-L4, L4-L5, L5-S1) $(p<0.001)$. There was no asymmetry between the right/left CSA and TCSA of the groups. Fat infiltration differed according to gender $(p=0.001)$ and segments $(p<0.001)$.

Conclusion: Fat infiltration in the lumbar multifidus muscle was associated with mechanical low back pain and lumbar discopathy. The fact that there was no difference between the cross-sectional area and the total cross-sectional area between the groups indicates the need to measure the FCSA or muscle atrophy due to fat infiltration in the evaluation of muscle mass, rather than CSA and TCSA.

\section{Background}

Low back pain (LBP) is a common problem with social, psychological and economic burdens [1]. It is the second most common reason for consulting a doctor after upper respiratory tract infections [2], and the most common cause of activity limitation in individuals under the age of 45 years [3]. It is estimated that $15-20 \%$ of adults experience low back pain once a year, and $50-80 \%$ experience at least one attack of back pain at some point in their lifetime [1]. This situation causes long-term morbidity and consequent loss of workforce, thereby becoming a costly socioeconomic health problem [4]. Although LBP is seen so frequently, the pathophysiology is still not fully understood and there is insufficient correlation between research findings and symptoms [2]. The causes of low back pain include lifestyle, working conditions, 
traumatic events, demographic characteristics, congenital malpharmacy, infectious, inflammatory, metabolic, neurogenic, neoplasic and many other factors [1].

Paraspinal muscles play a role in the structural and functional stabilization of the lumbar spine. Paraspinal muscles consist of a superficial muscle layer responsible for spine and extremity movements and a deep muscle layer that primarily controls intersegmental movement [5]. The primary task of the paraspinal muscles is to extend the spine. It also helps lateral flexion when the erector spinae (L.ES) moves unilaterally. Biomechanical and morphological studies have shown that lumbar muscular multifidus (L.MF) has a good capacity for segmental support and is insufficient to generate torque. On the other hand, while L.ES muscle creates a good torque, it is not as effective as lumbar multifidus for spinal orientation control [6, 7]. Compared to all lumbar muscles, L.MF is short, thick and has a large cross-sectional area (CSA). These properties enable the L.MF to generate enormous forces in a short time and make the L.MF ideal for stability. In contrast to the multisegmental innervation of the paraspinal musculature, L.MF has unilateral innervation originating from the medial branch of the posterior root of the segmental nerve [8]. This makes this muscle the most common and quickly affected muscle of LBP.

Muscle degeneration is morphologically characterized by a decrease in muscle size and increased adipose tissue accumulation $[9,10]$. Paraspinal muscle size has been associated with gender, Body Mass Index (BMI), physical activity level and family history [11-17]. It has been reported that the combined effects of familial genes and the shared early environment are the strongest determinants of paraspinal muscle parameters [15]. Studies have shown that there is $9 \%$ fat infiltration in the paraspinal muscles in healthy middle-aged volunteers [10]. Magnetic resonance imaging (MRI) as a non-invasive way to evaluate the structure and composition of paraspinal muscle tissue, which has recently become more widely used to characterize diseases and evaluate response to injury or changes due to mechanical stress $[19,20]$. MRI provides high resolution, contrast and a clearer image of soft tissue in the evaluation of muscle CSA and fat infiltration without exposure to radiation. The reliability of MRI has also been shown to be slightly better than computed tomography scanning [18].

There is no study in the literature that has compared healthy individuals with patients with mechanical low back pain and those with lumbar discopathy in the same study. The aim of this study was to examine the morphology of the multifidus and erector spinae muscles in healthy individuals and patients with chronic low back pain of mechanical and discopathy origin, and to determine whether different approaches are required for these groups, especially in the treatment of chronic low back pain. The secondary aim was to evaluate the relationship between the size of the paraspinal muscles and fat infiltration and the subject's age, gender, BMI, segmental (L3-L4, L4-L5, L5-S1) involvement levels, pain duration and severity.

\section{Material And Method}

\section{Participants}


The study was conducted between November 2020 and February 2021 with 90 participants. Group 1 comprised of 30 healthy individuals randomly selected from volunteers who had been invited through social media and announcements, had no defined back pain for the last year, and had no back problems in examination and radiology. Group 2 comprised 30 patients with non-specific (idiopathic) mechanical low back pain who presented at the Orthopedics and Traumatology Department with low back pain and no additional lumbar problems detected in examination, radiology and laboratory tests. Group 3 included 30 patients with lumbar discopathy on MRI, and radicular pain not due to root compression and no symptoms. EMG was requested from patients in case of suspected root compression. In all 3 groups, the subjects were aged 20-65 years. Group 2 and Group 3 patients were randomly selected from patients with a 3-month history of low back pain. Low back pain was accepted as pain defined between the lower border of the LBP ribs and the gluteal fold. Those with a history of inflammatory (ankylosing spondylitis), infectious, metabolic, neoplastic, hip and pelvic disorders, short legs, neurogenic, vertebral fractures, structural deformities (scoliosis, kyphosis), malformations and lumbar surgery were excluded from the study. Demographic, clinical and disease-related data were obtained through face-to-face interviews in all the groups. Hemogram, erythrocyte sedimentation rate, complete urinalysis, ASO, CRP, RF, salmonella and brucella tests were requested from the patients when it was deemed necessary for differential diagnosis. Pain severity was evaluated using a Visual Analogue Scale (VAS). The examinations of all 90 patients were analyzed by the same physician experienced in spine surgery, and lumbar spine MR images were analyzed by the same radiologist, an experienced consultant blinded to the clinical history. MRI scans were obtained by the same radiology technician in all cases. Written informed consent was provided by all participants before inclusion in the study. Approval for the study was granted by the local Ethics Committee (YDU/2020/83-1160).

\section{Measurements}

\section{Magnetic Resonance Imaging}

Imaging was performed using a 1.5 Tesla MRI device (Signa Explorer SV25.3 with updated software, 16 channels, General Electric, Milwaukee, WI, USA). Following the adjustment of the patient's localization in the supine position, the L3-S1 cross section was performed with a routine protocol for the lumbar spine to be taken from the center of the disc. Evaluations were made in turbo supine echo T1-T2 weighted saggital and T2 axial 4mm sections parallel to the disc spaces. L.ES and L.MF L3-S1 level, right and left, CSA, TCSA (L.MF + L.ES), fat content and asymmetry were evaluated. The interobserver reliability for MRI was reported to be moderate and the intraobserver reliability excellent by Kalichman et al [21].

There is no consensus on sequences using both T1 and T2 weighted sequences in MRI. In most studies, degeneration was graded by axial images. In evaluations, it has been stated that muscle, fat and facial structures are easier to identify and separate anatomically with T2-weighted sections (Fig. 1) [22].

For this study, the fascial boundaries of the CSA muscles were determined and quantitatively measured using Packs Report imaging and manually drawn. Fat infiltration of the muscles was evaluated as semi- 
quantitative. In evaluation, grade 1: refers to a normal (fat infiltration up to $10 \%$ of the muscle crosssectional area), grade 2 : moderate (10-50\%), and grade 3 : severe ( $>50 \%)$ fat infiltration (Fig. 2$)[2,8,21,23]$.

For internal reliability, 13 randomly selected patients were reassessed by the same radiologist one month later. When the intraobserver agreement was examined with kappa, the obtained kappa value was 0.941 .

\section{Statistical evaluation}

Data were analyzed with IBM SPSS vn.23 software (Chicago, IL, USA). Considering the average values of CSA, the minimum sample size to be included in the study was determined to be 78 , with $95 \%$ confidence (1-a), 95\% test strength (1- $\beta$ ) and $f=0.461$ effect size. The study was completed with over 90 subjects to take potential patient losses into consideration. According to PostHoc Power analysis, the power of the test with 90 subjects was found to be $97.7 \%$ [25]. Conformity of the data to normal distribution was examined with the Kolmogorov-Smirnov test. The Kruskal Wallis and Mann Whitney $\mathrm{U}$ tests were used to compare data that were not normally distributed. The main effects of group, gender, and segment on cross-sectional areas and total cross-sectional area were examined with the MANOVA test, taking age and $\mathrm{BMI}$ as covariate variables. The Bonferroni test was used in multiple comparisons. Categorical data were compared using the Chi-square test. A value of $p<0.05$ was accepted as statistically significant.

\section{Results}

The demographic characteristics of the current study patients according to the groups are presented in Table 1. In this analysis, age and BMI were put in the model as covariate variables. In the covariate variable, it was aimed to control the effects of age and BMI values on dependent variables.

Table 1 Comparison of the age, gender, BMI, pain duration, and pain intensity of the patients according to the groups

\begin{tabular}{|c|c|c|c|c|c|c|c|c|c|}
\hline & \multicolumn{2}{|r|}{ Group 1} & \multicolumn{2}{|r|}{ Group 2} & \multicolumn{2}{|r|}{ Group 3} & \multicolumn{2}{|r|}{ Total } & \multirow[t]{2}{*}{$P$} \\
\hline & $\bar{x} \pm \sigma$ & Median (min-max) & $\bar{x} \pm \sigma$ & Median (min-max) & $\bar{x} \pm \sigma$ & Median (min-max) & $\bar{x} \pm \sigma$ & Median (min-max) & \\
\hline Age(years) & $32.4 \pm 8.19$ & $33(21-48)^{n}$ & $\begin{array}{l}32.67 \pm \\
9.09\end{array}$ & $28.5(23-56)^{a}$ & $42.5 \pm 6.27$ & $44,5(27-51)^{6}$ & $\begin{array}{c}35,86 \pm \\
9,16\end{array}$ & $36(21-56)$ & $\leqslant 0,001^{1}$ \\
\hline \multirow{2}{*}{$\begin{array}{l}\mathrm{BMI}\left(\mathrm{kg}^{2} \mathrm{~m}^{2}\right) \\
\text { LBPP pain } \\
\text { duration }(\mathrm{m})\end{array}$} & $\begin{array}{c}25.01 \pm \\
3.58\end{array}$ & $24.41(19.25-32.79)^{\mathrm{sb}}$ & $\begin{array}{c}24.76 \pm \\
5.32\end{array}$ & $23.2(18.08-36.63)^{2}$ & $\begin{array}{c}28.07 \pm \\
4.63 \\
48.1 \pm\end{array}$ & $27,51(20,24-36,2)^{b}$ & $\begin{array}{c}25,95 \pm \\
4,76 \\
33,95 \pm\end{array}$ & $\begin{array}{c}25,16(18,08- \\
36,63)\end{array}$ & \multirow{2}{*}{$\begin{array}{l}0,010^{1} \\
0,022^{2}\end{array}$} \\
\hline & - & -- & $19.8 \pm 29.8$ & $6(3-120)$ & 55.02 & $36(3-240)$ & 46,13 & $10(3-240)$ & \\
\hline VAS rest & - & -- & $1.77 \pm 0.82$ & $2(1-4)$ & $2.47 \pm 1.38$ & $2(1-6)$ & $2,12 \pm 1,18$ & $2(1-6)$ & $0,052^{2}$ \\
\hline VAS activity & - & -- & $3.23 \pm 0.97$ & $3(2-6)$ & $4.43 \pm 1.81$ & $4(2-8)$ & $3,83 \pm 1,56$ & $3(2-8)$ & $0,009^{2}$ \\
\hline Gender & \multicolumn{2}{|r|}{$\mathrm{n}(\%)$} & \multicolumn{2}{|r|}{$\mathrm{n}(\%)$} & \multicolumn{2}{|r|}{$n(\%)$} & & & \\
\hline Male & \multicolumn{2}{|r|}{$13(43.3)$} & \multicolumn{2}{|r|}{$7(23.3)$} & \multicolumn{2}{|r|}{$8(26.7)$} & & $28(31.1)$ & \multirow{2}{*}{$0.200^{3}$} \\
\hline Female & \multicolumn{2}{|r|}{$17(56.7)$} & \multicolumn{2}{|r|}{$23(76.7)$} & \multicolumn{2}{|r|}{$22(73.3)$} & \multicolumn{2}{|r|}{$62(68.9)$} & \\
\hline
\end{tabular}

${ }^{1}$ Kruskal Wallis, ${ }^{2}$ Mann Whitney U, ${ }^{3}$ Pearson Chi Square, VAS (VIsual Analog Scale), LBP: Low back pain, BMl: body mass index, m:month, a-a: There is no difference between groups with the same letter, a-b-ab: There is a difference between groups with different letters. 


\section{Investigation of CSA and TCSA by groups}

CSA mean value (Table 2) differed only in the right L.MF and healthy group $(\mathrm{p}=0.011)$. The average CSA value in Group 1 was lower than in Group 2 and Group 3. There was no difference between the groups in TCSA in other muscle groups. There was no difference between Group 2 and Group 3.

Table 2 Descriptive statistics by groups ( $\mathrm{mm} 2)$

\begin{tabular}{|c|c|c|c|c|}
\hline & Parameter & Group 1 & Group 2 & Group 3 \\
\hline \multirow[t]{4}{*}{ CSA } & Right musculus multifidus $\left(\mathrm{mm}^{2}\right)$ & $\begin{array}{l}934.36 \pm \\
264.05^{a}\end{array}$ & $\begin{array}{l}968.87 \pm \\
301.57^{b}\end{array}$ & $\begin{array}{l}1036.74 \pm \\
291.75^{b}\end{array}$ \\
\hline & Left musculus multifidus $\left(\mathrm{mm}^{2}\right)$ & $\begin{array}{l}947.18 \pm \\
265.14\end{array}$ & $\begin{array}{l}947.13 \pm \\
295.38\end{array}$ & $\begin{array}{l}1018.41 \pm \\
287.11\end{array}$ \\
\hline & Right erector spinae $\left(\mathrm{mm}^{2}\right)$ & $\begin{array}{l}1669.24 \pm \\
456.47\end{array}$ & $\begin{array}{l}1588.69 \pm \\
581.23\end{array}$ & $\begin{array}{l}1799.63 \pm \\
492.89\end{array}$ \\
\hline & Left erector spinae $\left(\mathrm{mm}^{2}\right)$ & $\begin{array}{l}1709.66 \pm \\
466.18\end{array}$ & $\begin{array}{l}1598.44 \pm \\
563.83\end{array}$ & $\begin{array}{l}1809.17 \pm \\
521.59\end{array}$ \\
\hline \multirow[t]{2}{*}{ TCSA } & $\begin{array}{l}\text { Right musculus multifidus, erector } \\
\text { spinae }\left(\mathrm{mm}^{2}\right)\end{array}$ & $\begin{array}{l}2603.6 \pm \\
458.23\end{array}$ & $\begin{array}{l}2557.56 \pm \\
663.64\end{array}$ & $\begin{array}{l}2836.38 \pm \\
564.46\end{array}$ \\
\hline & $\begin{array}{l}\text { Left musculus multifidus, erector } \\
\text { spinae }\left(\mathrm{mm}^{2}\right)\end{array}$ & $\begin{array}{l}2656.83 \pm \\
477.35\end{array}$ & $\begin{array}{l}2545.58 \pm \\
636.81\end{array}$ & $\begin{array}{l}2827.58 \pm \\
574.53\end{array}$ \\
\hline
\end{tabular}

b-b: no difference between groups with the same letter, a-b-: There is a difference between groups with different letters, CSA:Cross-sectional area, TCSA: Total cross-sectional area

The mean CSA and TCSA values differed in all muscle groups according to gender $(p<0.001)$ (Table 3 ). In all three groups, the CSA and TCSA values were higher in males than females.

No relationship was determined between age and the CSA and TCSA in the healthy group (Table 3). A moderate positive correlation was found in the mechanical low back pain group $(p<0.05)$, and a weak positive correlation was found in the lumbar hernia group $(p<0.05)$.

According to segments (L3-L4, L4-L5, L5-S1) (Table 3), cross-sectional areas differed statistically in all groups ( $p<0.001$ ). In all groups, the largest L.MF CSA was found in L5-S1, and the smallest in the L3-L4 segment, while the largest L.ES CSA was found in L3-4 and the smallest in the L5-S1 segment. In the side comparison (asymmetry) (Table 2), CSA did not differ between the right / left sides among all groups.

A positive weak, medium level relationship was determined between BMI and CSA and TCSA in Group $1(p<0.05)$, a positive weak, moderate relationship in Group $2(p<0.05)$ and a positive moderate relationship in Group $3(p<0.05)$ (Table 3). 
In terms of pain, no relationship was found between Group 2 and Group 3 between the duration of low back pain and the CSA and TCSA of the muscles. A negative weak relationship was found between resting pain intensity and CSA and TCSA in Group $2(p<0.05)$. While there was no correlation between activity pain intensity and CSA of the muscles, a weak negative correlation was found with TCSA ( $p$ $<0.05)$. In Group 3, no significant relationship was found between resting and activity pain intensity and muscle CSA and TCSA.

Table 3 Comparisons of the CSA and TCSA of the groups according to gender, segment, age, BMI

\begin{tabular}{llccccccccccc}
\hline & \multicolumn{2}{c}{ Group } & \multicolumn{2}{c}{ Gender } & \multicolumn{2}{c}{ Segment } & \multicolumn{2}{c}{ Age } & \multicolumn{2}{c}{ BMI } \\
\hline & & $\mathrm{p}$ & $\eta^{2}$ & $\mathrm{p}$ & $\eta^{2}$ & $\mathrm{p}$ & $\eta^{2}$ & $\mathrm{p}$ & $\eta^{2}$ & $\mathrm{p}$ & $\eta^{2}$ \\
\hline CSA & R.LMF & $\mathbf{0 . 0 1 1}$ & 0.034 & $<\mathbf{0 . 0 0 1}$ & 0.124 & $<\mathbf{0 . 0 0 1}$ & 0.587 & 0.186 & 0.007 & $\mathbf{0 . 0 0 6}$ & 0.029 \\
& L.LMF & 0.073 & 0.020 & $<\mathbf{0 . 0 0 1}$ & 0.172 & $<\mathbf{0 . 0 0 1}$ & 0.593 & 0.833 & 0.000 & $<\mathbf{0 . 0 5}$ & 0.051 \\
& R.LES & 0.652 & 0.003 & $<\mathbf{0 . 0 0 1}$ & 0.106 & $<\mathbf{0 . 0 0 1}$ & 0.179 & 0.722 & 0.000 & $<\mathbf{0 . 0 5}$ & 0.180 \\
& L.LES & 0.460 & 0.006 & $<\mathbf{0 . 0 0 1}$ & 0.067 & $<\mathbf{0 . 0 0 1}$ & 0.159 & 0.194 & 0.006 & $<\mathbf{0 . 0 5}$ & 0.185 \\
TCSA & R.LMF-LES & 0.218 & 0.012 & $<\mathbf{0 . 0 0 1}$ & 0.173 & $\mathbf{0 . 0 4 6}$ & 0.023 & 0.837 & 0.000 & $<\mathbf{0 . 0 5}$ & 0.192 \\
& L.LMF-LES & 0.271 & 0.010 & $<\mathbf{0 . 0 0 1}$ & 0.151 & 0.062 & 0.021 & 0.259 & 0.005 & $<\mathbf{0 . 0 5}$ & 0.220 \\
\hline
\end{tabular}

R:Right, L: Left, LMF: lumbar musculus multifidus LES: Lumbar Erector Spinae, BMI: Body Mass Index, CSA:Cross-sectional area, TCSA: Total cross-sectional area, १2: Partial Eta Square

\section{Analysis of fat infiltration according to groups}

When the fat infiltrations were examined (Table 4), the right L.MF, left L.MF, and left L.ES differed between the groups ( $p=0.011, p=0.001, p=0.027$, respectively). Right L.ES did not differ between groups $(p=0.0192)$. While the rate of fat infiltration $<10 \%$ was higher in Group 1 than in Group 2 and Group 3, it was determined that $10-50 \%$ and $>50 \%$ fat infiltration was higher in Group 2 and Group 3 than in Group 1.

Table 4 Examination of fat infiltrations in groups (Simplified 3 degree system) 


\begin{tabular}{|c|c|c|c|c|c|}
\hline & Group 1 & Group 2 & Group 3 & Total & $P^{*}$ \\
\hline \multicolumn{6}{|c|}{ Fat infiltration R.L.MF } \\
\hline$<10 \%$ & $38(42.2)^{a}$ & $17(18.9)^{b}$ & $27(30)^{\mathrm{ab}}$ & $82(30.4)$ & \multirow[t]{3}{*}{0.011} \\
\hline $10-50 \%$ & $52(57.8)^{a}$ & $71(78.9)^{b}$ & $62(68.9)^{\mathrm{ab}}$ & $185(68.5)$ & \\
\hline$>50 \%$ & $0(0)$ & $2(2.2)$ & $1(1.1)$ & $3(1.1)$ & \\
\hline \multicolumn{6}{|c|}{ Fat infiltration L.L.MF } \\
\hline$<10 \%$ & $39(43.3)^{\mathrm{a}}$ & $15(16.7)^{\mathrm{b}}$ & $31(34.4)^{a}$ & $85(31.5)$ & \multirow[t]{3}{*}{0.001} \\
\hline $10-50 \%$ & $51(56.7)^{\mathrm{a}}$ & $72(80)^{b}$ & $58(64.4)^{\mathrm{ab}}$ & $181(67)$ & \\
\hline$>50 \%$ & $0(0)$ & $3(3.3)$ & $1(1.1)$ & $4(1.5)$ & \\
\hline \multicolumn{6}{|c|}{ Fat infiltration R.L.ES } \\
\hline$<10 \%$ & $33(36.7)$ & $21(23.3)$ & $30(33.3)$ & $84(31.1)$ & \multirow[t]{3}{*}{0.192} \\
\hline $10-50 \%$ & $56(62.2)$ & $64(71.1)$ & $57(63.3)$ & $177(65.6)$ & \\
\hline$>50 \%$ & $1(1.1)$ & $5(5.6)$ & $3(3.3)$ & $9(3.3)$ & \\
\hline \multicolumn{6}{|c|}{ Fat infiltration L.L.ES } \\
\hline$<10 \%$ & $34(37.8)^{a}$ & $22(24.4)^{b}$ & $31(34.4)^{\mathrm{ab}}$ & $87(32.2)$ & \multirow[t]{3}{*}{0.027} \\
\hline $10-50 \%$ & $55(61.1)$ & $61(67.8)$ & $58(64.4)$ & $174(64.4)$ & \\
\hline$>50 \%$ & $1(1.1)$ & $7(7.8)$ & $1(1.1)$ & $9(3.3)$ & \\
\hline
\end{tabular}

* Chi-square test, R.L.MF: Right Lumbar Musculus Multifidus, L.L.MF: Left L.MF, R.L.ES: Right Lumbar Erector Spinae, L.L.ES: Left L.ES, a-a: There is no difference between groups with the same letter, a-b-ab: Different letters There is a difference between groups that have

Fat infiltration by gender differed between groups (right and left L.MF, right and left L.ES) $(p=0.001$, $p=0.001, p=0.009, p=0.002$, respectively). In all groups, a higher rate of fat infiltration was observed in females than in males.

In the relationship between age and fat infiltration, only a weak negative correlation was found between left L.MF ( $r=0.123, p=0.043)$. There was no significant relationship between age and other muscles in respect of fat infiltration. There was no relationship between $\mathrm{BMI}$ and fat infiltration values of the muscles.

Fat infiltration differed according to segments (L3-L4, L4-L5, L5-S1) $(\mathrm{p}<0.001)$. In the right L.MF, the lowest fat infiltration was at L3-L4, and the highest at L5-S1, in the left L.MF the lowest was at L3-L4 and 
the highest at L4-L5 / L5-S1. In the right L.ES, the lowest was at L3-L4 and the highest fat infiltration was at L4-L5 / L5-S1, and in the left L.ES, the lowest was at L3-L4 and the highest at L5-S1.

In terms of pain duration and severity, in Group 3, a weak positive correlation was found between the duration of pain and only left L.ES fat infiltration $(p<0.05)$.

\section{Discussion}

Measurement of the morphology of lumbar paraspinal muscles has become the focus of recent studies on the etiology of LBP $[2,5,9-11,24]$. It has been suggested that dysfunction of these muscles is an important factor in the etiology and chronicity of low back pain [10,24]. Studies have shown a relationship between paraspinal muscle atrophy, low back pain $[2,9-12,15,25,26]$ and fat infiltration $[10,22,23,27-30]$. However, many researchers have reported no significant differences in paraspinal muscle size $[16,29-34]$ or fat content $[9,11,24]$ compared with healthy individuals. In the current study, no significant relationship was found between low back pain and the CSA and TCSA of L.MF and L.ES. There may be no reduction in size of dystrophic muscles. This phenomenon is known as pseudohypertrophy in which fat deposits settle in muscle fibers [10]. Impaired neuromuscular function in low back pain may cause histological changes in the muscle, which may cause atrophy [23]. However, the muscle area may not be decreased due to fat infiltration in the muscle bundles [21]. Muscle density is an indicator of muscle degeneration and refers to the number of muscle fibers, individual muscle fiber area, and the totality of contractile material [35]. Cross-section mainly refers to the total number of muscle fibers together with to a lesser extent the size of the fibers [15] and the amount of fat in the muscle [12]. In the current study, although it was not statistically significant, it was observed that the amount of muscle visualised in axial sections was less in Groups 2 and 3 than in the healthy group, whereas in Group 2 and Group 3, both statistically and visually, fat infiltration was higher than in the healthy group. That there was no difference in CSA between the groups can be considered to be due to the fact that the crosssectional areas did not change due to the increased fat infiltration rate in individuals with chronic low back pain, despite the decreased functional cross-sectional area (FCSA) of the muscles. Therefore, it is important to look at FCSA instead of cross-sectional area or total cross-sectional area to determine whether there is a loss of mass in the muscles in order to give clearer results.

Studies have indicated greater cross-sectional area and higher paraspinal muscle density in males than females, younger individuals have more muscle density than older adults, and individuals of normal weight have higher paraspinal muscle density than those who are overweight [34]. In the current study, the muscle cross-sectional areas and total cross-sectional areas of males were found to be higher than those of females in all the groups in accordance with the literature $[2,8,11-14,18]$. A higher rate of fat infiltration was determined in females than in males, which was consistent with findings in literature [17, $21,23,36]$.

It has been stated that $\mathrm{BMI}$ and body weight are associated with larger muscle cross-sectional area [16]. Some authors have reported a significant correlation between BMI and L.MF and L.ES muscle values, and 
that BMI was associated with paraspinal muscle changes [15]. In contrast, other studies have been shown no relationship between BMI and cross-sectional area [10, 23, 25]. Kalichman et al. found a low but statistically significant negative correlation between paraspinal muscle density and BMI, and the relationship between paraspinal muscle density and BMI was insignificant in males but significant in females [21]. In the current study, a weak and moderate relationship was found between BMI and CSA and TCSA.

Similar to the findings of previous studies in the literature, in this study, according to segments (L3-L4, L4L5, L5-S1), the cross-sectional area and total cross-sectional area were determined to be the lowest at L3L4 and the highest at L5-S1 level in all groups [8, 10, 25, 33, 37-39].

Most studies in literature have compared the asymmetry between acute, chronic, with and without root compression, and between symptomatic and asymptomatic sides $[8,11,38-40)$. The results of a study conducted on healthy subjects showed that L.MF is symmetrical on both sides. In a study of asymptomatic subjects between 1992 and 1994, Hides et al. showed a 3\% $\pm 4 \%$ difference between the sides [37]. Stokes et al. recently reported this rate as 7.2-9.6\% compared to the smallest margin at the L4L5 level [14]. Based on these results, it was stated that asymmetry of $>10 \%$ could be seen as potentially abnormal [21]. In the current study results of asymmetry, no significant difference was found between the cross-sectional areas in all the groups. This result was thought to be due to the balanced distribution of fat infiltration in the muscles, especially in the mechanical low back pain and lumbar hernia group, as the pain was acute, unilateral and there was no root compression.

In studies conducted at one-week, one-month, six-months, one-year, and 15-year follow-ups to reveal the estimated relationship between cross-sectional area and low back pain, it has been shown that there is an estimated relationship between cross-sectional area and low back pain over 12 months [41]. While studies showing a relationship between pain intensity and cross-sectional area are limited [5], similar to the results of the current study, those studies have generally shown no relationship between pain intensity and cross-sectional area [2, 25, 36, 42].

Fat infiltration appears to be a late stage of muscle degeneration, with L.MF fat infiltration common in adults and particularly strongly associated irrespective of body composition [23]. In obese individuals, body fat naturally accumulates in the muscles along the back musculature but does not settle at the level of the last two lumbar vertebrae where spinal problems are common. The presence of fat infiltration mainly in these two problem areas tends to indicate that it is the back pain that initiates the muscle changes [21]. In the literature, there is no clarity about the relationship between fat infiltration and chronic low back pain $[30,41,43]$. While some studies have reported a relationship between only L.MF and fat infiltration in chronic low back pain $[23,27,28]$, others have reported an association of fat infiltration in both L.MF and L.ES $[2,23,27,29-31]$. There are also studies reporting no relationship between L.MF and / or L.ES and fat infiltration. [9, 11]. In the current study, while an increase in fat infiltration was detected in L.MF muscle in individuals with chronic low back pain compared to healthy individuals, no significant increase was observed in L.ES muscle. The degeneration seen in the L.MF muscle in individuals with 
chronic low back pain could be attributed to the anatomy, function and innervation features of this muscle.

The amount of intramuscular fat increases significantly in the lower lumbar vertebrae segments compared to the upper lumbar segments in L.MF and L.ES [21]. More paraspinal muscle atrophy (fat infiltration) in L5-S1 than in L3-L4 may be associated with a higher rate of spinal pathology and degeneration occurring at this level. The size of the angle between the L5-S1 level, which is the highest weight bearing and the most mobile spine level, greatly increases the stress in the vertebral unit. These factors are likely to be the cause of the paraspinal muscle changes observed at the relevant level [15]. Similar to previous findings in literature, the results of the current study showed fat infiltration to be lowest at L3-L4 and highest at L5-S1 according to L.MF and L.ES segments [2, 9, 21, 38].

In Group 2, there was no significant relationship between pain duration and pain intensity and fat infiltration. In Group 3, a weak positive correlation was found between the duration of pain and only left L.ES fat infiltration. No significant relationship was found between pain intensity and fat infiltration. In previous studies on the relationship between L.MF fat infiltration and low back pain, no significant relationship has been found between fat infiltration for periods of less than one year or above one year, and limited evidence has been reported [41]. The current study results were consistent with the literature.

The limitation of this study was the lack of compatibility between age and BMI between the herniated disc and other groups. However, age and BMI index were put in the model as covariate variables and their effects were controlled.

\section{Conclusion}

Fat infiltration in the lumbar multifidus muscle is associated with mechanical low back pain and lumbar hernia. Evaluation of muscle mass should be made by measuring FCSA or muscle atrophy due to fat infiltration instead of CSA, and TCSA. This may explain the absence of a relationship between chronic low back pain and CSA and TCSA. The results in the mechanical low back pain and lumbar hernia group were similar, and the presence of high fat infiltration in the L.MF muscle requires appropriate lumbar stabilization exercises in both groups to preserve the functions of this muscle. Mechanical low back pain and lumbar hernia without root compression are not associated with paraspinal muscle asymmetry. A higher rate of fat infiltration was seen in females than in males. Fat infiltration is often seen in the lower lumbar vertebral levels (L4-5, L5-S1) and often in the muscle area adjacent to the vertebral body. TCSA and CSA were found to be associated with body mass index, but not with age, pain duration and severity.

\section{Abbreviations}

L.MF: Lumbar Musculus Multifidus, L.ES: Lumbar Musculus Erector Spinae, MRI: Magnetic Resonance Imaging, CSA: Cross-sectional area, TCSA: Total cross-sectional area, VAS: Visual Analogue Scale, LBP: Low back pain, BMI: Body Mass Index. 


\section{Declarations}

\section{Ethics approval and consent to participate}

The present study has been performed in accordance with the Declaration of Helsinki and was approved by the Ethics Committee of the Near East University Ethics Review Board (YDU/2020/83-1160). All participants were informed about the study procedure and provided informed consent.

\section{Consent for publication}

Not applicable.

\section{Availability of data and materials}

The datasets generated during and analyzed during the current study are not publicly available due to local administrative procedures ethics regulations but are available from the corresponding author on reasonable request.

\section{Competing interests}

The authors declare that they have no conflict of interests.

\section{Funding}

No funding was obtained for this study.

\section{Authors' contributions}

A.Y. and T.Y. conceived the study, interpreted the data and were the main contributors in writing the manuscript. A.O. managed the study. A.Y. assessed the patients for eligibility and referred potential participants to the outpatient clinic. All authors reviewed, amended and approved the final manuscript.

\section{Acknowledgements}

The authors would like to thank Radiology Specialist Doctor Kerim Temiz for his contributions in the interpretation of patient magnetic resonance images (MRI), technician Halil ibrahim Efe who performed the MRI scans, and Application specialist İbrahim Yesilyurt who helped adapt the MRI device for the study.

\section{References}

1. Rubin DI. Epidemiology and risk factors for spine pain. Neurol Clin 2007; 25: 353-371. https://doi.org/10.1016/j.ncl.2007.01.004.

2. Kader DF, Wardlaw D, Smith FW. Correlation between the MRI changes in the lumbar multifidus muscles and leg pain. Clin Radiol 2000; 55: 145-9. https://doi.org/10.1053/crad.1999.0340. 
3. Andersson GBJ. Epidemiology of low back pain. Acta Orthop Scand. 1998;69(281): 28-31. https://doi.org/10.1080/17453674.1998.11744790

4. Katz JN. Lumbar disc disorders and low-back pain: socioeconomic factors and consequences. J Bone Joint Surg Am 2006; 88(2): 21-4. https://doi.org/10.2106/JBJS.E.01273.

5. Fortin M, Gibbons LE, Videman T, Battié MC. Do variations in paraspinal muscle morphology and composition predict low back pain in men? Scand J Med Sci Sports 2015: 25: 880-887. https://doi.org/10.1111/sms.12301

6. Jorgensen K, Mag C, Nicholaisen T, Kato M. Muscle Fibre Distribution, Capillary Density And Enzymatic Activities In The Lumbar Paravertebral Muscles Of Young Men. Significance For Isometric Endurance. Spine, 1993; 18:1439-1450.

7. Kaigle AM, Holm SH, Hansson TH. Experimental Instability In The Lumbar Spine. Spine, 1995; 20(4):421-430. https://doi.org/10.1097/00007632-199502001-00004

8. Min JH, Choi HS, Rhee WI, Lee Jl. Association between radiculopathy and lumbar multifidus atrophy in magnetic resonance imaging. J Back Musculoskelet Rehabil. 2013; 26:175-181. https://doi.org/10.3233/BMR-13036

9. Danneels LA, Vanderstraeten GG, Cambier DC, Witvrouw EE, De Cuyper HJ. CT imaging of trunk muscles in chronic low back pain patients and healthy control subjects. Eur Spine J 2000: 9 (4): 266-272. https://doi.org/10.1007/s005860000190.

10. Parkkola R, Rytokoski U, Kormano M. Magnetic resonance imaging of the discs and trunk muscles in patients with chronic low back pain and healthy control subjects. Spine. 1993;18:830-836. https://doi.org/10.1097/00007632-199306000-00004.

11. Hides J, Gilmore C, Stanton W, Bohlscheid E. Multifidus size and symmetry among chronic LBP and healthy asymptomatic subjects. Man Ther. 2008;13(1): 43-49. https://doi.org/10.1016/j.math.2006.07.017.

12. Kalichman L, Hodges P, Li L, Guermazi A, Hunter DJ. Changes in paraspinal muscles and their association with low back pain and spinal degeneration: CT study. European Spine Journal, 2010;19(7):1136-1144. https://doi.org/10.1007/s00586-009-1257-5

13. Kalichman L, Klindukhov A, Li L, Linov L. Indices of paraspinal muscles degeneration: reliability and association with facet joint osteoarthritis: feasibility study. J Spinal Disord Tech. 2016; 29(9): 465470. https://doi.org/10.1097/BSD. 0b013e31828be943

14. Stokes M, Rankin G, Newham DJ. Ultrasound imaging of lumbar multifidus muscle: normal reference ranges for mea- surements and practical guidance on the technique. Man Ther. 2005;10(2):116-126. https://doi.org/10.1016/j.math.2004.08.013.

15. Fortin M, Videman T, Gibbons LE, Battie MC. Paraspinal muscle morphology and composition: a 15yr longitudinal magnetic resonance imaging study. Med Sci Sports Exerc 2014;46:893-901. https://doi.org/10.1249/ MSS.0000000000000179

16. Gibbons LE, Videman T, Battie MC, Kaprio J. Determinants of paraspinal muscle cross-sectional area in male monozygotic twins. Phys Ther. 1998;78(6):602-12. https://doi.org/10.1093/ptj/78.6.602. 
17. Takayama K, Kita T, Nakamura H, Kanematsu F, Yasunami T, Sakanaka H, et al. New predictive index for lumbar paraspinal muscle degeneration associated with aging. Spine. 2016;41(2): E84-E90. https://doi.org/10.1097/BRS.0000000000001154.

18. Hu ZJ, He J, Zhao FD, Fang XQ, Zhou LN, Fan SW. An assessment of the intra - and inter - reliability of the lumbar paraspinal muscle parameters using CT scan and magnetic resonance imaging. Spine. 2011; 36(13): E868-74. https://doi.org/10.1097/BRS.0b013e3181ef6b51.

19. D'Aprile P, Tarantino A, Jinkins JR, Brindicci D. The value of fat saturation sequences and contrast medium administration in MRI of degenerative disease of the posterior/perispinal elements of the lumbosacral spine. Eur Radiol 2007;17:523-531. https://doi.org/10.1007/s00330-006-0324-0.

20. Kumar $Y$, Hayashi D. Role of magnetic resonance imaging in acute spinal trauma: a pictorial review. BMC Musculoskelet Disord. 2016; 17: 310. https://doi.org/10.1186/s12891-016-1169-6

21. Kalichman L, Carmeli E, Been E. The Association between Imaging Parameters of the Paraspinal Muscles, Spinal Degeneration, and Low Back Pain. Exp Ther Med. 2017; 2562957: 1-14. https://doi.org/10.1155/2017/2562957

22. Upadhyay B, Toms AP. CT and MRI evaluation of paraspinal muscle degeneration. Europen Cociety of Radiology. 2015;C-2114. https://doi.org/10.1594/ecr2015/C-2114

23. Kjaer P, Bendix T, Sorensen JS, Korsholm L, Leboeuf-Yde C. Are MRI-defined fat infiltrations in the multifidus muscles associated with low back pain? BMC Med. 2007: 5: 2. https://doi.org/10.1186/1741-7015-5-2

24. Lee HJ, Lim WH, Park JW, Kwon BS, Ryu KH, Lee JH, et al. The relationship between cross sectional area and strength of back muscles in patients with chronic low back pain. Ann Rehabil Med 2012: 36(2): 173-181. https://doi.org/10.5535/arm. 2012.36.2.173

25. Kamaz M, Kiresi D, Oguz H, Emlik D, Levendoglu F. CT measurement of trunk muscle areas in patients with chronic low back pain. Diagn Interv Radiol. 2007: 13(3): 144-148.

26. Beneck GJ, Kulig K. Multifidus atrophy is localized and bilateral in active persons with chronic unilateral low back pain. Arch Phys Med Rehabil 2012: 93(2): 300-306. https://doi.org/10.1016/j.apmr.2011.09.017.

27. Mengiardi B, Schmid MR, Boos N, Pfirrmann CWA, Brunner F, Elfering A,et al. Fat content of lumbar paraspinal muscles in patients with chronic low back pain and in asymptomatic volunteers: quantification with MR spectroscopy. Radiology 2006: 240(3): 786-792. https://doi.org/10.1148/radiol.2403050820.

28. Gildea JE, Hides JA, Hodges PW. Size and symmetry of trunk muscles in ballet dancers with and without low back pain. J Orthop Sports Phys Ther. 2013;43:525-33. https://doi.org/10.2519/jospt.2013.4523

29. Teichtahl AJ, Urquhart DM, Wangetal Y. Fat infiltration of paraspinal muscles is associated with low back pain, disability, and structural abnormalities in community-based adults. Spine Journal. 2015; 15(7): 1593-1601. https://doi.org/10.1016/j.spinee.2015.03.039. 
30. Suri P, Fry AL, Gellhorn AC. Do muscle characteristics on lumbar spine magnetic resonance imaging or computed tomography predict future low back pain, physical function, or performance? A systematic review. PM\&R 2015;7:1269-81. https://doi.org/10.1016/j.pmrj.2015.04.016.

31. McLoughlin RF, D'Arcy EM, Brittain MM, Fitzgerald O, Masterson JB. The significance of fat and muscle areas in the lumbar paraspinal space: a CT study. J Comput Assisted Tomogr. 1994: 18 (2): 275-278. https://doi.org/10.1097/00004728-199403000-00021

32. Ploumis A, Michailidis N, Christodoulou P, Kalaitzoglou I, Gouvas G, Beris A. Ipsilateral atrophy of paraspinal and psoas muscle in unilateral back pain patients with monosegmental degenerative disc disease. Br J Radiol. 2011: 84(1004): 709-713. https://doi.org/10.1259/bjr/58136533

33. D'Hooge R, Cagnie B, Crombez G, Vanderstraeten G, Dolphens M, Danneels L. Increased intramuscular fatty infil- tration without differences in lumbar muscle cross-sectional area during remission of unilateral recurrent low back pain. Man Ther. 2012 17(6): 584-588. https://doi.org/10.1016/j.math.2012.06.007.

34. Cuellar WA, Wilson A, Blizzard CL, Otahal P, Callisaya ML, Jones G, et al. The assessment of abdominal and multifidus muscles and their role in physical function in older adults: a systematic review. Physiotherapy. 2017; 103(1): 21-39. https://doi.org/10.1016/j.physio. 2016.06.001.

35. Jones DA, Rutherford OM, Parker DF. Physiological changes in skeletal muscle as a result of strength training. Q J Exp Physiol. 1989; 74: 233-256. https://doi.org/10.1113/expphysiol.1989.sp003268

36. Mannion AF, Kaser L, Weber E, Rhyner A, Dvorak J, Muntener M. Influence of age and duration of symptoms on fibre type distribution and size of the back muscles in chronic low back pain patients. Eur Spine J. 2000; 9(4): 273-281. https://doi.org/10.1007/s005860000189

37. Hides JA, Saide M, Stokes MJ, Jull GA, Cooper DH. Evidence of lumbar multifidus muscle wasting ipsilateral to symptoms in patients with acute/subacute low back pain. Spine. 1994;19(2):165-172. https://doi.org/10.1097/00007632-199401001-00009.

38. Barker KL, Shamley DR, Jackson D. Changes in the cross-sectional area of multifidus and psoas in patients with unilateral back pain: the relationship to pain and disability. Spine. 2004; 29: E515E519. https://doi.org/10.1097/01.brs.0000144405. 11661.eb.

39. Kim WH, Lee S, Lee DY. Changes in the cross-sectional area of multifidus and psoas in unilateral sciatica caused by lumbar disc herniation. J Korean Neurosurg Soc. 2011: 50 (3): 201-204. https://doi.org/10.3340/jkns.2011.50.3.201

40. Yoshihara K, Shirai Y, Nakayama Y, Uesaka S. Histo-chemical changes in the multifidus muscle in patients with lumbar intervertebral disc herniation. Spine. 2001; 26(6):622-626. https://doi.org/10.1097/00007632-200103150-00012.

41. Ranger TA, Cicuttini FM, Jensen TS, Peiris WL, Hussain SM, Fairley J, et al. Is the size and composition of the paraspinal muscles associated with low back pain? A systematic review. Spine J 2017; 17: 1729-48. https://doi.org/10.1016/j.spinee. 2017.07.002.

42. Ranger TA, Cicuttini FM, Jensen TS, Heritier S, Urquhart DM. Paraspinal muscle cross-sectional area predicts low back disability but not pain intensity. Spine J. 2019;19(5):862-868. 
https://doi.org/10.1016/j.spinee.2018.12.004.

43. Fortin M, Macedo L. Multifidus and paraspinal muscle group cross-sectional areas of patients with low back pain and control patients: a systematic review with a focus on blinding. Phys Ther. 2013: 93 (7): 873-888. https://doi.org/10.2522/ptj.20120457.

\section{Figures}

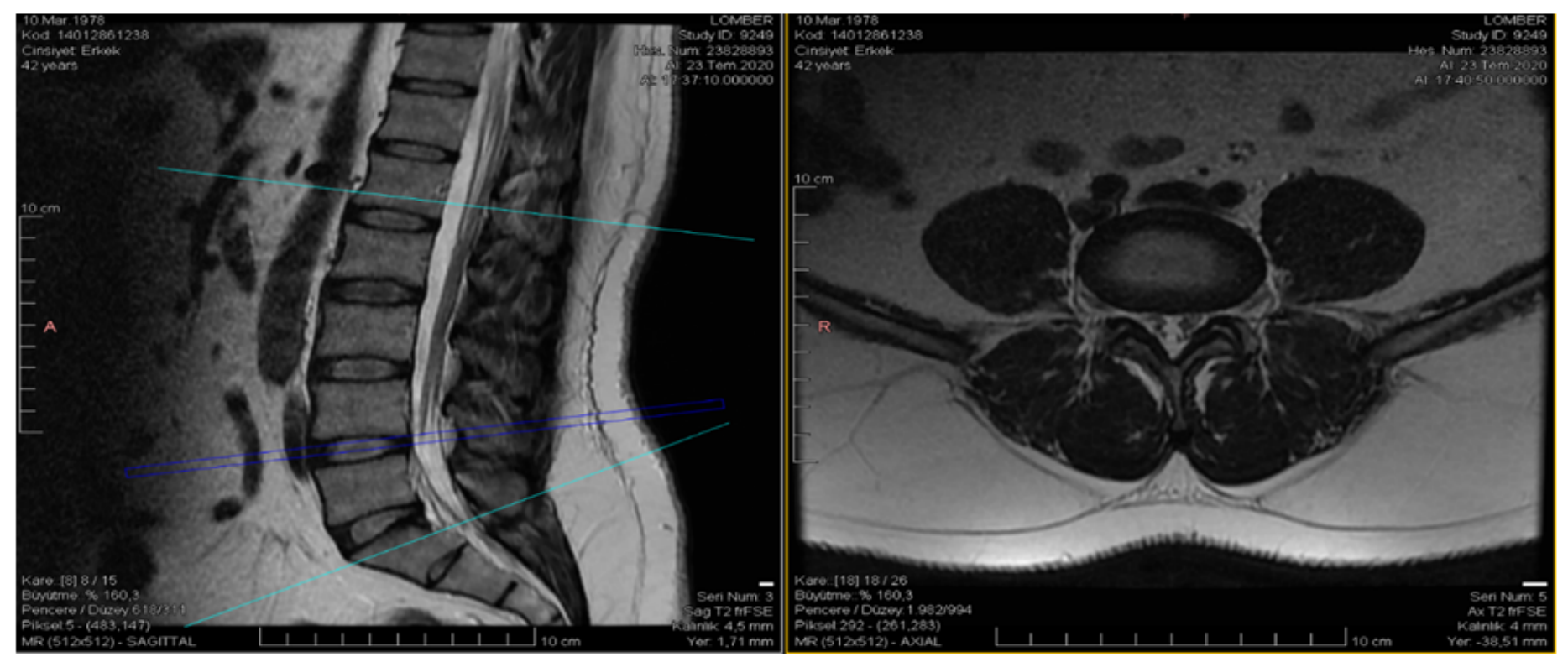

\section{Figure 1}

L4-L5, T2 Sagittal and axial MRI cross section from a subject in the healthy group. 


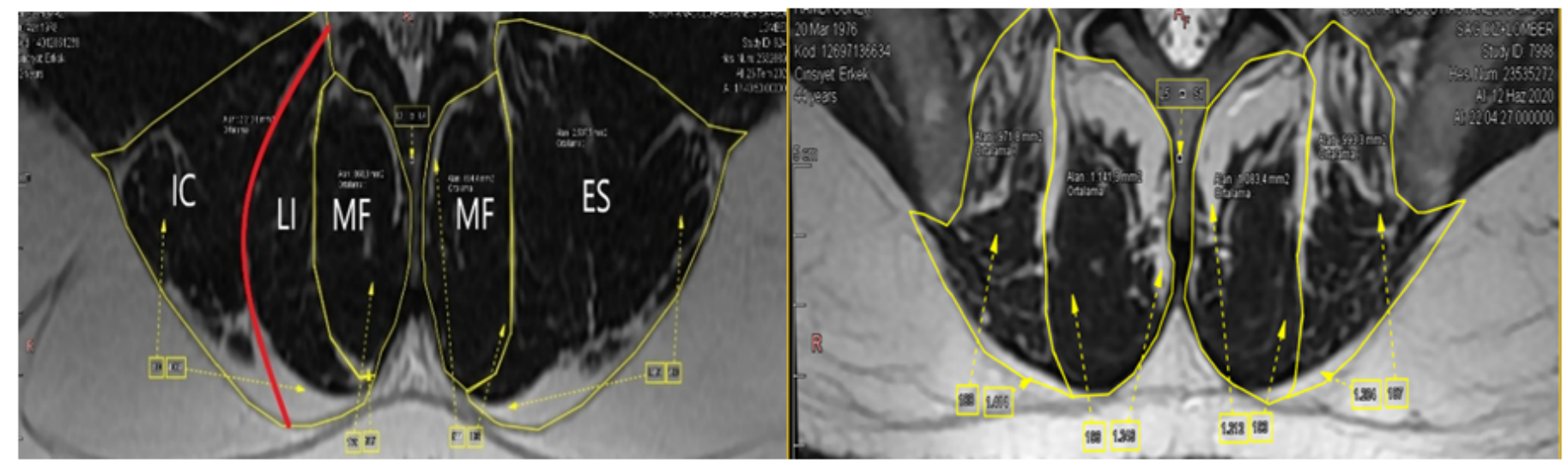

(A)

(B)

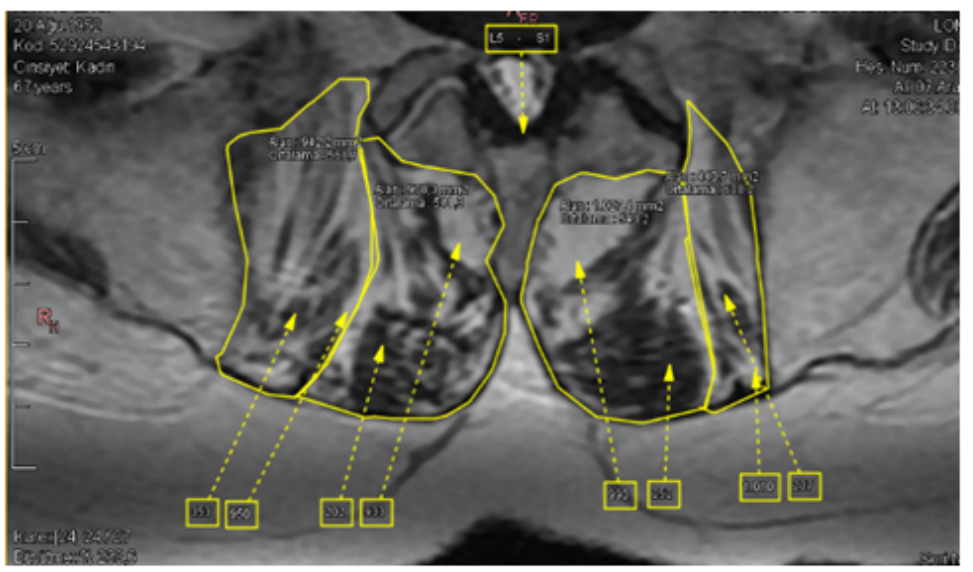

(C)

\section{Figure 2}

Location of muscles and degrees of fat infiltration on T2 axial MRI section (A) Musculus multifidus (MF), Musculus erector spinae (ES), Musculus longissimus (LI), Musculus iliocostalis (IC) and Grade 1: $<10 \%$ fat infiltration (B) Grade 2: 10-50\% fat infiltration (C) Grade 3:> 50\% fat infiltration 